\title{
A LASER MANAGEMENT IN CASES OF LARYNGEAL STENOSIS DUE TO CORROSIVE POISONING
}

\section{${ }^{* 1}$ Dr. Nilam Uttam Sathe, 2Dr. Swapnal Sawarkar, ${ }^{2}$ Dr. Ashwin Gaikwad and ${ }^{2}$ Dr. Lal Pek Thangi}

${ }^{1}$ Associate Professor, ENT Dept, Seth G. S. Medical College and KEM Hospital, Parel, Mumbai - 400012

${ }^{2}$ Senior ENT Restdent, ENT Dept, Seth G. S. Medical College and KEM Hospital, Parel, Mumbai - 400012

\section{ARTICLE INFO}

\section{Article History:}

Received $03^{\text {rd }}$ March, 2021

Received in revised form

$11^{\text {th }}$ April, 2021

Accepted $21^{\text {st }}$ May, 2021

Published online $26^{\text {th }}$ June, 2021

Key Words:

Laser; Laryngeal stenosis.

\begin{abstract}
Background: Post corrosive poisoning result in serious chemical injuries and complications to the gastrointestinal tract and a high mortality rate. Post corrosive Complications that include respiratory injuries are especially significant for determining the severity of acute corrosive poisonings. Mortality is most often caused by tracheal necrosis, perforation of esophagus or stomach, followed by Mediastinitis or peritonitis. Results: Herewith presenting nine cases of laryngotracheal stenosis following corrosive poisoning ingestion. The purpose of this study is to upper aerodigestive tract complications and its Management. Stricture can be managed by endoscopic dilatation, oesophageal Stents, surgery. In our experience we planned for laser release of cricopharyngeal stricture with oesophageal dilatation. Diode laser isused for release of cricopharyngeal. Conclusions: Good postoperative outcome can be achieved and patient can be without tracheostomy for life long living near normal life. Pre and post operative psychological analysis and counselling is also very important for better functional outcome.Giving general anaesthesia is challenging in these cases hence experienced Team of anaesthetist is required to prevent mortality.
\end{abstract}

Copyright (C) 2021, Dr. Nilam Uttam Sathe et al. This is an open access article distributed under the Creative Commons Attribution License, which permits unrestricted use, distribution, and reproduction in any medium, provided the original work is properly cited.

Citation: Dr. Nilam Uttam Sathe, Dr. Swapnal Sawarkar, Dr. Ashwin Gaikwad and Dr. Lal Pek Thangi, 2021. “A laser management in cases of laryngeal stenosis due to corrosive poisoning", International Journal of Development Research, 11, (06), 47920-47923.

\section{INTRODUCTION}

Post corrosive poisoning result in serious chemical injuries and complications to the gastrointestinal tract and a high mortality rate. Post corrosive Complications that include respiratory injuries are especially significant for determining the severity of acute corrosive poisonings. Mortality is most often caused by tracheal necrosis, perforation of esophagus or stomach, followed by Mediastinitis or peritonitis. The purpose of this study is to upper aerodigestive tract complications and its Management.

\section{CASE REPORT}

Case 1: 50 year old female came with history of corrosive acid ingestion. Post corrosive Ingestion patient developed oesophageal stricture for that patient had undergone multiple oesophageal dilatation but the patient symptoms not improved. Patient had undergone esophagostomy with string insertion with feeding jejunostomy. Patient had complaints of aspiration, dysphagia, change in voice and breathlessness. On airway assessment small epiglottis adhered to the base of tongue, both vocal cords mobile, narrowing of cricopharynx.The laryngeal inlet anatomy was distorted. Patient was breathing through tracheostomy. Diode laser excision was used to release the bands between epiglottis and base tongue in the first sitting.
Vallecular adhesive bands were released in the second siting using diode lasr after interval of one moth following first laser surgery and simultaneously pyriform aperture was feed from the bands. .Patient followed after one month, three months and six months. Now she is havimg no complaints of aspiration, breathlessness or change in voice. Tracheostomy tube has been removed after airway assessment. Patient does not have breathlessness. But still has mild dysphagia.

Case 2: 38 year old male came with the history of corrosive ingestion. Patient's general Condition was stable. Oral mucositis, oropharyngeal ulcers managed conservatively. Persistent dysphagia, aspiration patient referred for upper Gastrointestinalscopy. Oesophageal and supraglottic stricture identified. Diode laser was used and these strictures of supraglottic area between vallecula and base were released. Patient followed after one month airway assessment was done. There was complete release of these supraglottic stricturs. Both the vocal cord movements were normal and there was no aspiration. Patient recovered without any morbidity.

Case 3: 18 Years old Male, with alleged h/o suicidal organophosphate poisoning in Feb 2018, was taken to a hospital, where he was intubated and kept on mechanical ventilation. After 15 days of mechanical ventilation, patient was extubated, following this patient started complaining of voice change and mild exertional dyspnoea, but no noisy breathing. Patient was then referred to our 
institute for further management. Airway assessment showed a grade 3 tracheal stenosis at $2^{\text {nd }}$ tracheal ring and left vocal cord palsy (FIG 1). Patient underwent elective tracheotomy and laser release of stenosis with bougie dialatation was done under general anaesthesia. Howeverafter one month on airway assessment again the stenosis was seen at $2^{\text {nd }}$ tracheal ring and there was no symptomatic improvement. Eventually he underwent surgical tracheoplasty with tibial periosteum with stent insertion, and had to undergo emergency stent removal with tracheotomy. Anaesthesia was given initially via tracheostoma and then shifted to nasotracheal ventilation. Patient however required an emergency tracheotomy and removal of stent. He was followed after one year and airway assessment was done. The tibial perichondrium was taken up and now patient is off the tracheostomy tube and breathing well and has recovered without any complications.
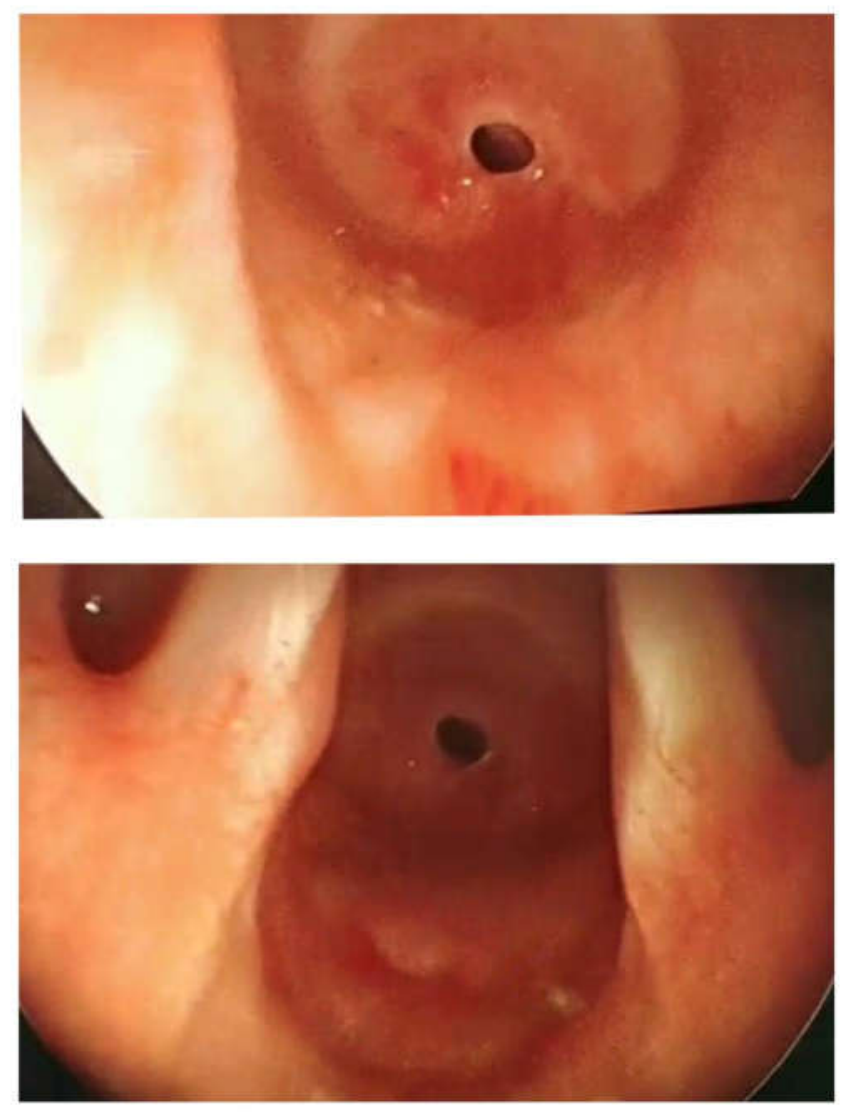

Fig. 1. Showing grade 3 tracheal stenosis at $2^{\text {nd }}$ tracheal ring and left vocal cord palsy

Case $4: 41$ years old Male presented with alleged history of suicidal organophosphate poisoning in November 2017. Patient was taken to government hospital and was intubated for 18 days. 15 days after extubation pt started complaining of exertional dyspnoea and noisy breathing. Patient underwent emergency tracheotomy at government hospital. Patient was then referred to our institute for further management with a metallic tracheostomy tube in situ. Airway assessment revealed right vocal cord palsy with dysphonea, plica ventricularis and anterior tracheal wall collapse and lateral wall collapse at $4^{\text {th }}$ and $5^{\text {th }}$ tracheal rings with normal tracheal rings below the site of stoma. $\mathrm{CO}_{2}$ LASER assisted release of supraglottic stenosis was done. Patient was eventually decannulated and has no respiratory complaint on follow up after three months postoperatively.

Case 5: 23 Years old Male, with alleged history of suicidal organophosphate poisoning in August 2016. Patient was intubated at a local hospital and underwent emergency tracheotomy in October 2016. Laser dialatation was done there. But patient had no symptomatic improvement and had dyspnoea. Hence Patient was then referred to our institute for further management. Airway assessment revealed grade 3 thick stenosis at $2^{\text {nd }}$ tracheal ring with 10 normal tracheal rings below the stoma. Patient underwent trachea-tracheal resection and anastomosis. Patient was given general anesthesia via tracheostomy tube and was later shifted to nasotracheal ventilation intraoperatively once anastomosis was done. Pt was extubated on table. He was following with us every 3 months. He has recovered without any complications.
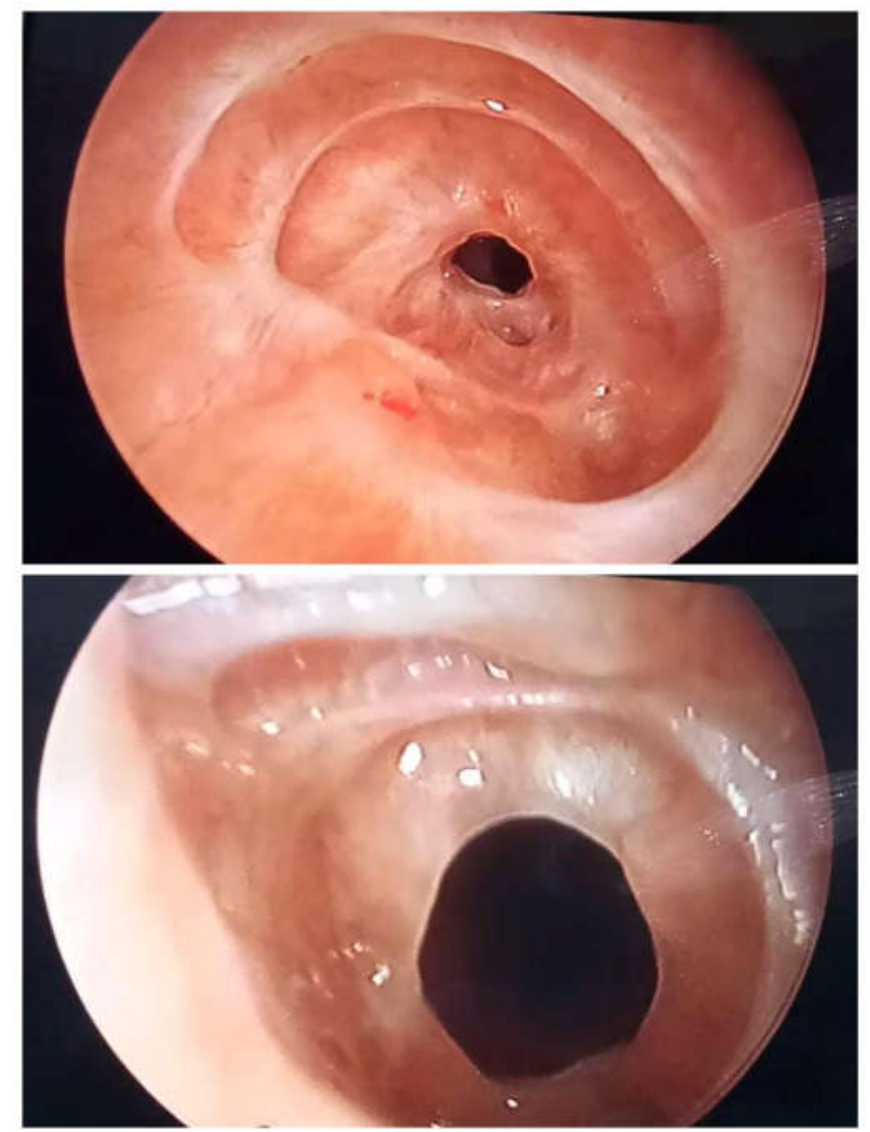

Fig. 2. Showing grade 2 tracheal stenosis from $2^{\text {nd }}$ to $4^{\text {th }}$ tracheal rings
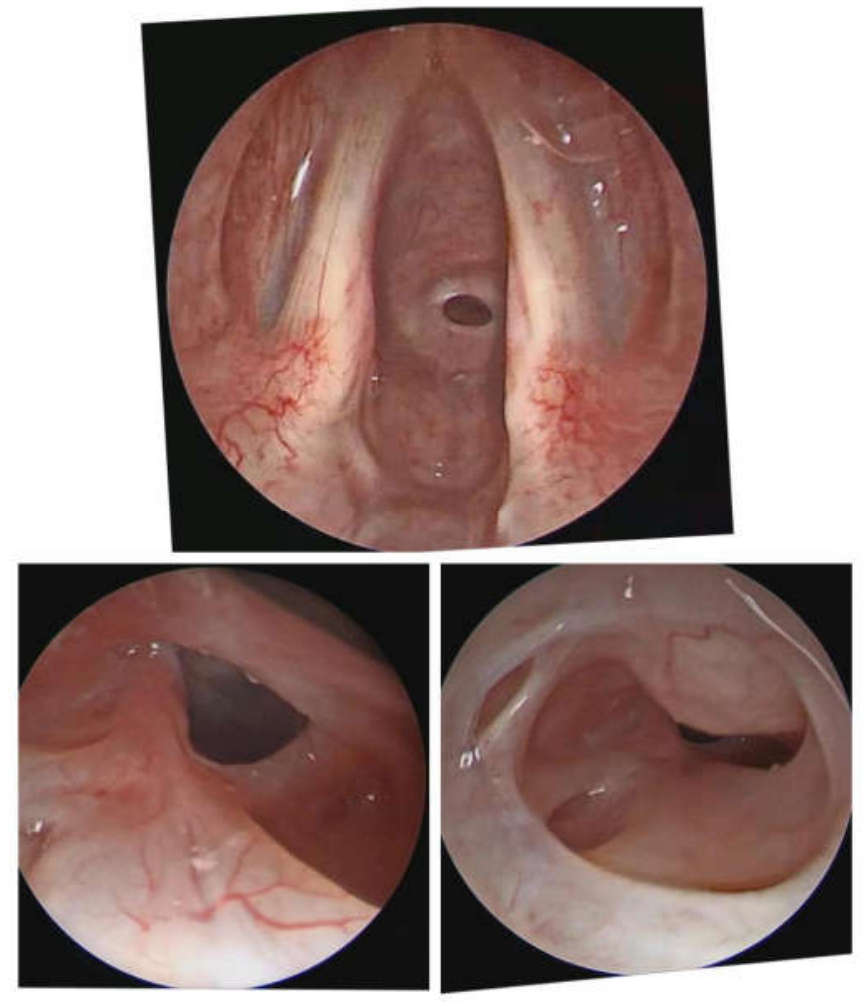

Fig. 3. Showing grade 1 circumferential membranous stenosis at $3^{\text {rd }}$ and $5^{\text {th }}$ tracheal rings 
Case 6: 19 Years old Male, with alleged history of suicidal organophosphate poisoning in October 2016, pt was on mechanical ventilation and was later extubated, however, few weeks after extubation, pt started complaining of noisy breathing and exertional dyspnea and underwent emergency tracheotomy at a private hospital in February 2017 and developed pneumothorax. Patient was then referred to our institute for further management. Airway assessment revealed grade 2 tracheal stenosis from $2^{\text {nd }}$ to $4^{\text {th }}$ tracheal rings (Fig2). Patient underwent bronchoscopic dilatation of stenosis in March 2017 and $\mathrm{CO}_{2}$ LASER assisted release of stenotic segment at $2^{\text {nd }}$ to $4^{\text {th }}$ tracheal rings in April 2017. Patient had to undergo tracheotracheal anastomosis as definitative treatment in 2019 and now he is free of tracheostomy tube and doing well without any complication.

Case 7: 25 Years old Female, came with alleged history of suicidal organophosphate poisoning in May 2018 and was intubated and kept on mechanical ventilation for 10 days at a local hospital. She was extubated after 10 days. She started complaining of noisy breathing and exertional dyspnea 8 days after extubation. Patient was then referred to our institute. Airway assessment revealed stenosis at two levels, grade 1 circumferential membranous stenosis at $3^{\text {rd }}$ and $5^{\text {th }}$ tracheal rings (Fig 3). Rigid bronchoscopy and bougie dilatation of membranous stenosis was done for this patient. Anaesthesia was achieved by intermittent apnoea technique and perioperative period was uneventful. Patient was extubated followed after one month and 6 months following laser surgery. She is breathing and phonating well and has recovered without any complications.

Case 8: 25 Years old Male with alleged history of suicidal organophosphate poisoning in Feb 2014, was admitted and kept on mechanical ventilation for a period of 2 weeks at a private hospital at Nashik. Patient was extubated and discharged, following this patient started complaining of progressive effort intolerance and stridor for which he underwent an emergency tracheotomy in March 2014. Endoscopic airway assessment at our institute done in April same year showed a hard fibrotic segment $2 \mathrm{~cm}$ in length, $2 \mathrm{~cm}$ below the cricoid, with $1 \mathrm{~cm}$ above the stoma and $1 \mathrm{~cm}$ below it . A repeat endoscopic airway assessment next year showed a grade 3 tracheal stenosis $1.5-2 \mathrm{~cm}$ in length, with preserved bilateral vocal cord mobility. Patient eventually underwent single stage tracheo-tracheal resection and anastomosis, postoperative course was uneventful.

Case 9: 23 Years old Male came with alleged history of suicidal organophosphate poisoning in July 2012, was admitted at a local private hospital and kept on mechanical ventilation for 15 days and then extubated. Patient has alleged history of suicidal organophosphate poisoning for a second time in 2013 for which he was kept on mechanical ventilation again for 2 weeks and then extubated and discharged. Since then patient has history of intermittent breathlessness and effort intolerance. Endoscopic airway assessment at our institute showed a grade 3 stenosis at subglottis. Patient underwent laser release of stenosis and twicw bronchoscopic assisted bougie dilatations thereafter. Anaesthesia during the procedures was achieved through intermittent apnoea technique. At present patient has no respiratory complaints. He has recovered only with laser dialatation surgery.

\section{DISCUSSION}

Corrosives are chemicals that cause tissue injury on contact by a chemical reaction ${ }^{2}$. Corrosives and caustics are synonyms. Acids and alkalis are two primary agents responsible for caustic exposures. Acid ingestion causes Coagulation necrosis whereas alkali ingestion causes liquefaction necrosis. Both acids and alkalis cause fibrosis and cicatrisation (stricture formation).Caustic injuries cause necrosis within seconds of exposure, ulceration and Perforation within 24-72 hours of exposure, fibrosis within 2 to 3 weeks of Exposure, stricture after weeks to years after exposure. Risk of malignancy After decades of exposure to alkali. Corrosive poisoning can manifest as variable degree of presentation in upper Gastrointestinal tract, oral mucositis, dysphagia, odynophagia, haematemesis. Perforation and death as acute complications. Stricture formation, gastric Outlet obstruction and malignant transformation are the chronic Complications. Routine blood investigation, electrolyte monitoring, plain chest X-ray shows gas shadow in the mediastinum or below the diaphragm suggestive Oesophageal or gastric perforation. CT computed tomography show the depth of necrosis, presence of Transmural damage thereby allows to assess the perforations. Diagnostic in the early evaluation of caustic injury. MRI does not reliably distinguish the Different layers of the oesophageal wall, necessary for the initial assessment of mucosal involvement. Endoscopy is highly recommended diagnostic test in the evaluation of caustic Injury especially during first 12 to 48 hours of caustic ingestion. Endoscopy is not advisable 5 to 15 days after caustic ingestion due to tissue softening and Friability during healing.

Endoscopy is not advisable when there is Hemodynamic instability, severe respiratory compromise, suspected Perforation ${ }^{22 .}$ Endoscopy is also helpful in staging the severity of inury, guide to Management and prognosis. Degree of oesophageal injury is a predictor of Systemic complications. Management includes immediate resuscitation and evaluation of extent of damage. $20 \%$ of caustic injuries with may not present with oropharyngeal injury. Mainstay of management is airway and hemodynamic Stabilisation. Respiratory distress is an emergency needs immediate intubation or emergency tracheostomy. Intubation with fibreoptic laryngoscoy ${ }^{1)}$ is best to avoid risk of bleeding and further injury. Supraglottic edema is an indication for Tracheostomy to secure the airway, neutralizing agents should not be administered due to additional thermal and chemical injury. Patient should be on fasting. Gastric acid suppression with histamine blockers and intravenous proton pump inhibitors for faster mucosal healing and to Prevent stress ulcers. Referral to gastroenterlogy department for endoscopy and colonesophagocoloplasty ${ }^{1,25}$. Severe oesophageal injuries requires close monitoring in ICU endoscopy, Endoscopy guided nasoenteric feeding tube insertion, and the patient should $\mathrm{Be}$ on nil per oral for 2 to 3 days ${ }^{12,15.23 .26}$. Patient general condition stable, and Improved after observation period oesophageal stricture is the most common Complication of caustic injury ${ }^{3,21}$. Stricture develops usually 8 th week of caustic Injury. Stricture can be managed by endoscopic dilatation, oesophageal Stents, surgery. In our experience we planned for laser release of cricopharyngeal stricture with oesophageal dilatation. Diode laser is used for release of cricopharyngeal Stricture by taking radial incision at 11,784 o clock position. Oesophageal Dilatation done by bougies 2 or 3 settings laser release has been done at an interval of 6 weeks. Post Procedure supraglottic stricture disappeared to a significant extent. Depending on the site of stenosis, patients symptoms severity and in generally the overall laryngotracheal anatomy was taken into consideration for choosing the treatment options. In most of the cases we have used diode laser for membranous stenosis. The patients who had thick stenosis we have used Diode laser and Bougie dialatation technique. All these patients have challenge in giving general anaesthesia to the patients ${ }^{4}$, 27. Intraoperative monitoring is equally important to prevent mortality. Most of the patients recovered only with laser dialatation. But few of them also required open airway surgery. Postoperative close follow up is must in these cases to prevent lifethreatening complications and morbidities. Pre and post operative psychological analysis and counselling is also very important for better functional outcome in these types of cases in addition to surgical treatment.

\section{Conclusion}

- $\quad$ Proper diagnosis and early intervention is must for treatment of aerodigestive stricture following corrosive ingestion.

- $\quad$ Pre and post operative psychological analysis and counselling is also very important for better functional outcome.

- Giving general anaesthesia is challenging in these cases hence experienced Team of anaesthetist is required to prevent mortality.

- Stricture can be managed by endoscopic lasr dilatation and oesophageal Stents, surgeries with good postoperative 
outcome and patient can be without tracheostomy for life long living near normal life.

Conflict of interest- There is no conflict of interest.

\section{REFERENCES}

Ananthakrishnan N, Parthasarathy G, Vikram K. Chronic Corrosive Injuries of the Stomach - A Single Unit Experience of 109 Patients Over Thirty Years, World J Surg. 2010; 34: 758-764.

Ananthakrishnan N, Subba Rao KSVK, Radjendiran P, Midcolonesophagocoloplasty for corrosive esophageal strictures. Aust N Z J Surg. 1993; 63: 389-395.

Andreoni B, Marini A, Gavinelli M, Biffi R, Tiberio G, Farina ML, Rossi A. Emergency management of caustic ingestion in adults. Surg Today. 1995; 25:119-124

Andreoni B, Marini A, Gavinelli M, Biffi R, Tiberio G, Farina, Rossi A. Emergency management of caustic ingestion in adults. Surg Today. 1995; 25: 119-124.

Bronstein AC, Spyker DA, Cantilena LR, Green J, Rumack BH, Heard SE. 2006 Annual Report of the American Association of Poison Control Centers' National Poison Data System (NPDS). ClinToxicol (Phila) 2007; 45: 815-917 [PMID: 18163234 DOI: $10.1080 / 15563650701754763]$

Caustic ingestion in children Andre weigertFRCA,Ann Black FRCA ,continuing education in Anaesthesia ,critical care \&pain, volume 5,2005

Cheng HT, Cheng CL, Lin CH, Tang JH, Chu YY, Liu NJ, Chen PC. Caustic ingestion in adults: the role of endoscopic classification in predicting outcome. BMC Gastroenterol 2008; 8: 31 [PMID: 18655708 DOI: 10.11846

Chibishev A, Pereska Z, Chibisheva V, Simonovska N. Ingestion of caustic substances in adults: a review article. IJT 2013; 6: 723734

Chibishev A, Sikole A, Pereska Z, Chibisheva V, Simonovska N, Orovchanec N. Severe renal function impairment in adult patients acutely poisoned with concentrated acetic acid. ArhHigRadaToksikol. 2013 Mar; 64(1): 153-158.

Chibishev A, Pareska Z, Chibisheva V, Simonovska N. Clinical and epidemiological features of acute corrosive poisonings. Med Arh. 2012; 66(3 Suppl 1): 11-15.

Chirica M, Veyrie N, Munoz-Bongrand N, Zohar S, Halimi B, Celerier M, Cattan P, Sarfati E. Late morbidity after colon interposition for corrosive esophageal injury: risk factors, management, and outcome. A 20-years experience. Ann Surg 2010; 252: 271-280 [PMID: 20622655 DOI: 10.1097/SLA.0b013e3181e8fd40]

Corrossive poisoning, R Raghu RamauluNaik, MVadivelan Indian journal of clinical practice Vol 23, no 3, 2012.
wDzhafarov ChM, DzhafarovECh. Surgical treatment of cicatricial stricture of the esophagus and stomach after chemical burn Khirurgiia (Mosk). 2007; (1): 25-28.

Ertekin C, Alimoglu O, Akyildiz H, Guloglu R, Taviloglu K. The results of caustic ingestions. Hepatogastroenterology. 51: 13971400

Gerzic ZB, Knezevic JB, Milicevic MN, Jovanovic BK Esophagocoloplasty in the management of postcorrosive strictures of the esophagus. Ann Surg 1990; 211: 329-336 [PMID: 2310239 DOI: 10.1097/00000658-199003000-00004]

Goldman LP, Weigert JM. Corrosive substance ingestion: a review. American Journal of Gastroenterology. 1984; 79(2): 85-90.

Javed A, Pal S, Dash NR, Sahni P, Chattopadhyay TK. Outcome following surgical management of corrosive strictures of the esophagus. Ann Surg 2011; 254: 62-66 [PMID: 21532530 DOI: 10.1097/SLA.0b013e3182125ce7

Kikendal JW. Caustic ingestion injuries. GastroenterolClin North Am. 1991; 20: 847-857.

Kikendall JN. Caustic ingestion injuries. GastroenterolClin North Am. 1991; 20: 847-857.

Lupa M, Magne J, Guarisco JL, Amedee R. Update on the diagnosis and treatment of caustic ingestion. Ochsner J 2009; 9: 54-59 [PMID: 21603414]

Management of esophageal caustic injury, Mark Anthony A De Lusong, Aeden Bernice G Timbol, Danny Joseph S TuazonWorld J Gastrointestinal PharmacolTher 2017

Panieri E, Rode H, and Millar AJ, Cywes S. Oesophageal replacement in the management of corrosive strictures: when is surgery indicated? Pediatr Surg Int 1998; 13: 336-340 [PMID: 9639611 DOI: $10.1007 / \mathrm{s} 003830050333$ ]

Ramasamy K, Gumaste VV. Corrosive ingestion in adults. J Clin Gastroenterol 2003; 37: 119-124 [PMID: 12869880 DOI: 10.1097/00 004836-200308000-00005]6/1471-230X-8-31]

Respiratory complications from acute corrosive poisonings in adults. AndonA, Chibishev, Natasa Simonovska, Cvetanka Bozinovska. Matersociomed 2014

Satar S, Topal M, Kozaci N. Ingestion of caustic substances by adults. Am J Ther 2004; 11: 258-261 [PMID: 15266217 DOI: 10.1097/01. mjt.0000104487.93653.a2]

Zargar SA, Kochhar R, Mehta S, Mehta SK. The role of fiberoptic endoscopy in the management of corrosive ingestion and modified endoscopic classification of burns. GastrointestEndosc 1991; 37: 165-169 [PMID: 2032601 DOI: 10.1016/S00165107(91)70678-0]

Zargar SA, Kuchhar R, Mehta S, et al. The role of fibroptic endoscopy in the management of corrosive ingestion and modified endoscopic classification of burns. GastrointestEndosc. 1991; 37: 165-169. 